\title{
Genetic deletion of Rnd3 suppresses apoptosis through NF-kB signaling in the brain
}

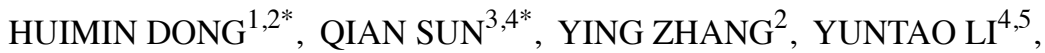 \\ FAN'EN YUAN $^{3,4}$, SHANPING MAO ${ }^{1}$ and BAOHUI LIU ${ }^{3,4}$ \\ ${ }^{1}$ Department of Neurology, Renmin Hospital of Wuhan University; ${ }^{2}$ Hubei Key Laboratory of Cell Homeostasis, \\ College of Life Sciences of Wuhan University, ${ }^{3}$ Department of Neurosurgery, Renmin Hospital of Wuhan University, \\ Wuhan University; ${ }^{4}$ Central Laboratory, Renmin Hospital of Wuhan University, Wuhan, Hubei 430060; \\ ${ }^{5}$ Department of Neurosurgery, Huzhou Central Hospital, Huzhou, Zhejiang 313000, P.R. China
}

Received January 20, 2020; Accepted September 15, 2020

DOI: $10.3892 /$ or.2020.7884

\begin{abstract}
Rho family GTPase 3 (RND3) is involved in multiple physiological activities involving the Rho kinase-dependent signaling pathway. The present study revealed a novel role of RND3 in the regulation of apoptosis in the brain. Using immunofluorescence and TUNEL assays, a decreased rate of brain apoptosis was observed in Rnd3-knockout mice. In addition, the function of RND3 in promoting apoptosis was determined in PC12 cells by immunoblotting assays and flow cytometry analysis in RNA interference and overexpression experiments. Furthermore, the present study demonstrated that Rnd3 and P65 protein interacted using immunoprecipitation analysis, and Rnd3 regulated apoptosis via its association with NF- $\mathrm{B}$ P65. Notably, Rnd3 blocked the anti-apoptotic action of $\mathrm{NF}-\kappa \mathrm{B}$ P65 in vitro by downregulating P65. Therefore, RND3-NF- $\kappa$ B P65 represents a novel signaling pathway in the regulation of brain apoptosis. The present study suggested an alternative approach for the treatment of neurodegenerative diseases through regulation of apoptosis via the RND3-NF- $\mathrm{B}$ P65 signaling pathway in the central nervous system.
\end{abstract}

\section{Introduction}

Apoptosis is the main form of programmed cell death that occurs during animal development and tissue homeostasis. It involves several stages, including progressive nuclear and

Correspondence to: Dr Baohui Liu or Dr Shanping Mao, Department of Neurosurgery, Renmin Hospital of Wuhan University, Wuhan University, 238 Jiefang Street, Wuhan, Hubei 430060, P.R. China

E-mail: bliu666@whu.edu.cn

E-mail: maospzy@163.com

*Contributed equally

Abbreviations: RND3, Rho family GTPase 3; RNAi, RNA interference

Key words: brain, apoptosis, central nervous system, Rho family GTPase 3, NF- $\mathrm{kB}, \mathrm{p} 65$ cytoplasmic shrinkage, chromatin condensation, and the shedding of apoptotic bodies (1). Following apoptosis, cell bodies are cleared by phagocytes or adjacent cells (2). At the molecular level, apoptosis is executed by caspase proteins, which cleave cellular substrates, leading to cell death (3). Apoptosis is an essential process that serves key roles in morphogenesis and tissue remodeling (4), and can also affect surrounding tissues by affecting cell division, cellular fate and the remodeling of nearby cells (5). Therefore, it is important to elucidate the underlying mechanism of cell apoptosis.

Apoptosis, also known as 'programmed cell death', has been identified throughout the process of mouse brain development. It is crucial for maintaining the circuits of the nervous system (6). Apoptosis occurs during in utero and early postnatal life (7-9). In the embryo, apoptosis affects different sites, including hindbrain neural folds at embryonic day (E)8-9, the lamina terminalis at E10.5-12.5, optic invagination at E11.5-12.5 (9), and the ventricular zone, intermediate zone and the developing cortical plate of the cerebral cortex at E12-18 $(10,11)$. Due to the low rate of relative apoptosis (0.14-0.35\% of cells per day), the process is difficult to identify histologically (10). However, evaluation of cleaved-caspase 3 levels or cell morphology using TUNEL assays can indicate the apoptosis rate (12). Apoptosis has been recognized in most sites of central development after birth, including the brain, spinal cord and peripheral ganglia (13). The precise time of the apoptosis rate peak varies, but cells mostly undergo apoptosis between postnatal day 0 (P0) and P14 (8). In the cortex, the apoptosis rate is highest between P4 and P8 (14). The final number of apoptotic neurons can range between 60 and $90 \%$ (14)

In addition to tissue development, apoptosis is associated with numerous pathologies. For example, defective apoptosis leads to proliferative diseases, such as cancer, excessive apoptosis has been linked to neurodegenerative disease (15), and the dysregulation of apoptosis is associated with stroke and traumatic brain injury $(16,17)$. The morbidity of neurodegenerative diseases is increasing worldwide; however, effective treatments and cures remain limited (18). A series of detrimental effects emerge during the development of neurodegenerative diseases, including mitochondrial dysfunction, inflammation 
and oxidative stress, which contribute to neuronal apoptosis, and inhibit nerve recovery and axon regeneration $(19,20)$.

Apoptosis can be categorized into two pathways: Intrinsic and extrinsic. Extrinsic apoptosis is initiated by the ligand-mediated activation of death receptors (21). Ligand binding leads to the activation of pro-caspase- $8(21,22)$, after which extrinsic apoptosis signaling converges with intrinsic apoptosis pathways at executioner caspases (2). Bax and BCL2 antagonist/killer 1 proteins are activated during intrinsic apoptosis, leading to the initiation of pathways that activate caspases, including mainly caspase-3, caspase- 6 and caspase-7 (23). Although the mechanisms underlying apoptosis are well known, its regulation is poorly understood.

$\mathrm{NF}-\mathrm{\kappa B}$ is a protein complex with a REL proto-oncogene $\mathrm{NF}-\kappa \mathrm{B}$ subunit (Rel) homology domain. The NF- $\kappa \mathrm{B}$ mammalian family contains five proteins: $\mathrm{p} 65, \mathrm{NF}-\kappa \mathrm{B} 1 / 2$ and Rel/RELB proto-oncogene NF- $\kappa \mathrm{B}$ subunit. NF- $\kappa \mathrm{B}$ proteins are widely expressed in developing and mature nervous systems, and NF- $\mathrm{KB}$ signaling has a neuroprotective function in the latter, where it protects neurons from glutamate-induced neurotoxicity and oxidative stress by enhancing the expression of brain-derived neurotrophic factors and the antiapoptotic gene Bcl-2 (24). NF- $\mathrm{kB}$ also activates the expression of genes involved in cell proliferation and protects against apoptosis (25). Although NF- $\mathrm{kB}$ has been implicated in the reduction of the neuronal apoptosis rate (26), its regulation is unclear.

Rho family GTPase 3 (RND3; also known as RhoE or Rho8) belongs to the RND subfamily of the Rho family of GTPases (27). The RND subfamily includes three members: RND1, RND2 and RND3. Most Rho family members function as molecular switches that cycle between the active GTP-bound form and the GDP-bound inactive form (28). In contrast to typical Rho family members, RND subfamily proteins can bind GTP but are resistant to GTPases, and are thus constitutively bound to GTP (29). RND3 was originally defined as a repressor of Rho protein kinase 1 (28). Previous studies on RND3 have focused mainly on its inhibitory effects on Rho kinase-mediated biological functions, including myosin light chain phosphorylation (30), actin cytoskeleton formation and apoptosis (31). RND3 is highly expressed in the mouse brain where it serves an essential role in neuronal development through its negative regulation of the Rho signaling pathway (32). Additionally, RND3 is associated with ependymal cell proliferation (33); however, its function in neuronal apoptosis remains unknown.

Genetic deletion of Rnd3 can have various effects on multiple organs. For instance, knocking out Rnd3 can result in aqueductal stenosis leading to hydrocephalus and heart calcium leakage which leads to heart failure in mice $(33,34)$. The present study demonstrated a novel function of Rnd 3 in the regulation of brain apoptosis using an Rnd3-knockout mouse model. The present study identified the molecular mechanism of Rnd3-mediated apoptosis and demonstrated that Rnd3 was a regulator of NF- $\kappa \mathrm{B}$ signaling in apoptosis. Furthermore, RND3 was demonstrated to interact with NF- $\mathrm{BB}$ P65 in vivo, which blocked the anti-apoptotic action of NF-кB P65 via the downregulation of $\mathrm{P} 65$. Therefore, the present study suggested the importance of RND3-NF- $\mathrm{BB}-\mathrm{P} 65$ signaling integrity in neurocyte apoptosis. The present findings may advance the understanding of apoptosis in the development of the nervous system, and may provide a potential target for pharmacologic manipulations in the treatment of neurodegenerative diseases.

\section{Materials and methods}

Rnd $3^{-/}$mouse lines. Rnd3-knockout mice were generated from a gene trap embryonic stem (ES) cell line at Texas Institute for Genomic Medicine (Texas, USA), provided by Dr Jiang Chang (Texas A\&M University Health Science Center, USA). The targeting vector was inserted into an Rnd 3 intron 2 as described previously (34). A total of 16 male mice (8 Rnd $3^{+/+}$ mice and 8 Rnd $3^{-}$mice; 7-day-old; weight, 4-5 g) were used and raised in specified pathogen-free conditions supplied with free access to sterilized water and UV-irradiated food, with an environment of $22^{\circ} \mathrm{C}$ and $60 \%$ humidity, 12-h light/dark cycle and noise $<60 \mathrm{~dB}$. Investigators were blinded to the mouse genotype and experimental group. Animals were identified by earmark numbers, which were unknown to the investigators until after the experiments and analyses were completed.

Immunostaining,immunoblotting(IB)andimmunoprecipitation $(I P)$. The following antibodies were used for the immune analyses: Anti-Rho8/Rnd3 [dilution, 1:1,000 for IB, 1:200 for IP, 1:100 for immunohistochemistry (IHC) and 1:50 for immunofluorescence (IF); cat. no. GTX81316; GeneTex, Inc.], anti-GAPDH (dilution, 1:200 for IB; cat. no. sc-25778; Santa Cruz Biotechnology, Inc.), anti-P65 (dilution, 1:200 for IB, 1:50 for IP and 1:25 for IF; cat. no. sc372; Santa Cruz Biotechnology, Inc.), anti-cleaved-caspase3 (dilution, 1:2,000 for IB and 1:100 for IF; cat. no. 9661; Cell Signaling Technology, Inc.), anti-caspase 3 (dilution, 1:200 for IB; cat. no. sc-7148; Santa Cruz Biotechnology, Inc.), anti-Myc-tag (dilution, 1:1,000 for IB; cat. nos. M047-3; Medical \& Biological Laboratories Co., Ltd.), anti-phospho-(p-)inhibitor of NF- $\kappa B-\alpha$ (dilution, 1:500 for IB; cat. no. 2859; Cell Signaling Technology, Inc.), anti-IкB- $\alpha$ (dilution, 1:500 for IB; cat. no. CSB-RA015761 A0HU; Cusabio Technology LLC), anti-Histone-H3 (dilution, 1:1,000 for IB; cat. no. GB11102; Wuhan Servicebio Technology Co., Ltd.), anti- $\beta$-tubulin (dilution, 1:1,000 for IB; cat. no. GB11017; Wuhan Servicebio Technology Co., Ltd.), anti-glial fibrillary acidic protein (dilution, 1:100 for IF; cat. no. 60190-1-lg; ProteinTech Group, Inc.), anti-neuronal nuclei (dilution, 1:100 for IF; cat. no. 26975-1-AP; ProteinTech Group, Inc.), HRP-goat anti mouse IgG (dilution, 1:2,000 for IB; cat. no. GB23301; Wuhan Servicebio Technology Co., Ltd.) and HRP-goat anti rabbit IgG (dilution, 1:2,000 for IB and 1:200 for IHC; cat. no. GB23303; Wuhan Servicebio Technology Co., Ltd.). The following fluorescent secondary antibodies were used: Donkey anti-goat IgG coupled with Alexa Fluor 488 (dilution, 1:200 for IF; cat. no. A11055; Invitrogen; Thermo Fisher Scientific, Inc.), goat anti-mouse IgG coupled with Alexa Fluor 488 (dilution, 1:200 for IF; cat. no. A11029; Invitrogen; Thermo Fisher Scientific, Inc.) and goat anti-rabbit IgG coupled with Alexa Fluor 594 (dilution, 1:200 for IF; cat. no. A11037; Invitrogen; Thermo Fisher Scientific, Inc.).

For IF and IHC analysis, previous protocols of tissue and cell sample preparation were adopted (35). Cell samples were fixed in $4 \%$ paraformaldehyde for $30 \mathrm{~min}$, while the tissues from 7-day-old mice brains were cut using a freezing 
microtome (CM1850; Leica Microsystems GmbH), fixed in 4\% paraformaldehyde for 2 weeks and then embedded in paraffin before use. Tissue sections (5- $\mu \mathrm{m}$-thick) were deparaffinized at $65^{\circ} \mathrm{C}$ for $2 \mathrm{~h}$, hydrated with $100 / 95 / 75 \%$ ethanol for $10 \mathrm{~min}$ each and antigen repaired with $10 \mathrm{mM}$ sodium citrate $(\mathrm{pH} 6.0)$ at $100^{\circ} \mathrm{C}$ for $20 \mathrm{~min}$. Tissue sections were incubated with $3 \%$ $\mathrm{H}_{2} \mathrm{O}_{2}$ to remove endogenous peroxidase and cell samples were permeabilized with $0.1 \%$ Triton $\mathrm{X}-100$ in PBS for $30 \mathrm{~min}$ at room temperature. Following treatment with 5\% BSA (cat. no. G5001; Wuhan Servicebio Technology Co., Ltd.) for $30 \mathrm{~min}$ at room temperature, the samples were incubated with primary antibody at $4^{\circ} \mathrm{C}$ overnight. After washing with PBS five times, the cells were subjected to the secondary antibody and incubated at room temperature. The nuclei were stained with DAPI for $10 \mathrm{~min}$ at room temperature. IHC experiments were performed using an avidin-biotin complex and diaminobenzidine tetrachloride (G1210-2; Wuhan Servicebio Technology Co., Ltd.). Images were captured under a confocal fluorescence microscope (FV1000; Olympus Corporation).

Tissue samples from 7-day-old mouse brains were homogenized in RIPA buffer $(50 \mathrm{mM}$ Tris- $\mathrm{HCl}$ at $\mathrm{pH} 8.0$, $0.15 \mathrm{M} \mathrm{NaCl}, 1 \mathrm{mM}$ EDTA and $0.5 \%$ NP-40) supplemented with a protease inhibitor cocktail (04693159001; Roche Diagnostics). Following centrifugation at $13,000 \mathrm{~g}$ at $4{ }^{\circ} \mathrm{C}$ for $15 \mathrm{~min}$, the supernatant fraction was first subjected to IP with a weight of $5 \mu \mathrm{g}$ for primary antibodies against P65, RND3 or pre-immune IgG (AR1010; Wuhan Boster Biological Technology, Ltd.) and incubated at $4^{\circ} \mathrm{C}$ for $4 \mathrm{~h}$. Subsequently, the samples were incubated with the beads of protein $G$ PLUS-agarose (Sc-2002; Santa Cruz Biotechnology, Inc.) in a low speed oscillation at $4^{\circ} \mathrm{C}$ overnight. Following washing with IP buffer (10 mM HEPES, $142.5 \mathrm{mM} \mathrm{KCl,} 5 \mathrm{mM} \mathrm{MgCl}$, $1 \mathrm{mM}$ EDTA and $0.5 \% \mathrm{NP}-40$ ), the samples were subjected to western blot analysis.

Western blot analysis was performed as previously described (36). Briefly, tissue and cell samples were lysed in RIPA buffer (Beyotime Institute of Biotechnology) with protease inhibitors (Roche Diagnostics). The protein concentrations were measured using a BCA kit (Beyotime Institute of Biotechnology). Protein samples (20 $\mu \mathrm{g} /$ lane) were separated on $12 \%$ SDS-polyacrylamide gels and then transferred onto 0.45-mm PVDF membranes (Merck KGaA). The membranes were incubated with anti-P65 or anti-RND3 antibodies overnight at $4^{\circ} \mathrm{C}$ after blocking with $5 \%$ skim milk powder (cat. no. G5002; Wuhan Servicebio Technology Co., Ltd.) at room temperature for $1 \mathrm{~h}$. The membranes were incubated with the indicated HRP-conjugated secondary antibody for $1 \mathrm{~h}$ after washing in TBST (20 mM Tris- $\mathrm{HCl} \mathrm{pH}$ 7.5, $150 \mathrm{mM} \mathrm{NaCl}, 0.1 \%$ Tween-20). A Super Signal Chemiluminescent Substrate system (k-12045-D50; Advansta, Inc.) was used to detect the signals. The amount of protein loaded in the IB analysis was verified by the intensity of the GAPDH blots. The specificity and sensitivity of the antibodies were validated based on the protocols used in our previous study (37). IB densitometry was performed using Image Lab (version 5.2; Bio-Rad Laboratories, Inc.).

Nuclear and cytoplasmic fractionation. Nuclear and cytoplasmic proteins were extracted using NE-PER nuclear-cytoplasmic extraction reagents (Thermo Fisher Scientific, Inc.) according to the manufacturer's protocols.
When measuring cytosolic and nuclear P65 protein expression, $\beta$-tubulin and histone $\mathrm{H} 3$ were used as cytoplasmic and nuclear loading controls, respectively.

Gene knockdown, cell culture and transfection. PC12 cells (derived from a pheochromocytoma, an embryonic origin from the neural crest; The Cell Bank of Type Culture Collection of the Chinese Academy of Sciences) and cultured in DMEM (Hangzhou Jinuo Biomedical Technology Co., Ltd.) with 5\% FBS (Gibco; Thermo Fisher Scientific, Inc.), 10\% horse serum (Gibco; Thermo Fisher Scientific, Inc.) and $1 \%$ penicillin/streptomycin (Hangzhou Jinuo Biomedical Technology Co., Ltd.). The transient transfection of all genes studied was performed using Lipofectamine 2000 (Invitrogen; Thermo Fisher Scientific, Inc.). Cells in each well of a 6-well plate were transfected with 100 pmol small interfering RNA (siRNA/si) or $2 \mu \mathrm{g}$ plasmid for $48 \mathrm{~h}$ prior to experimentation. The siRNA pools containing multiple siRNAs specific for $R n d 3$ and $p 65$, with non-targeting siRNAs used as controls, were purchased from Thermo Fisher Scientific, Inc. Dharmacon RNAi technologies (RND3, cat. no. L-007794-00-0005; p65, cat. no. L-040776-00-00010; and non-targeting siRNA, cat. no. D-001206-13-20; GE Healthcare Dharmacon, Inc.). Detailed information of siRNAs was described previously (38) and the sequences of siRND3, siP65 and siControl were 5'-CUACAGUGUUUGAGAAUUAUU-3', 5'-GATTGAGGA GAAACGTAAA-3' and 5'-CCTACGCCACCAATTTCGT-3'. The construction of $m y c-R N D 3$ and overexpression vectors was described previously (37).

Isolation of hippocampus in mice. A cut was made along the coronal and sagittal sutures and both sides of the parietal bone and interparietal bone were pulled off. To expose the hippocampus, the cerebral cortex covering it was removed. The first incision was made at the end of the hemisphere, extending no more than $\sim 0.7 \mathrm{~mm}$ deep to prevent nicking the adult mouse hippocampus while exposing it. The second incision was made $1.5-2 \mathrm{~mm}$ in front of the first one, and the lateral ventricle was cut into. Both incisions entered the ventral brain and met there. Both sides of the cortex that covered the hippocampus were pulled up along the ventricle. The remainder of the hippocampus was separated from the cortex by pulling the cortex along the surface of the hippocampus towards the ventral part of the hippocampus. Subsequently, the hippocampus was freed from the surrounding tissue.

TUNEL assay. Brain tissues from 7-day-old mice were fixed with $10 \%$ neutral buffered formalin at room temperature for 2 weeks, processed and trimmed for use in the TUNEL assay. After being embedded in paraffin, the samples were cut into $\sim 5-\mu \mathrm{m}$-thick slices. TUNEL assays were performed following the protocol of an in situ cell death detection kit (Roche Molecular Diagnostics). Samples were incubated in TUNEL reagent at $37^{\circ} \mathrm{C}$ in a wet dark box for $60 \mathrm{~min}$. Nuclei were stained with $0.5 \%$ hematoxylin at room temperature for $5 \mathrm{sec}$, and neutral resin was used as mounting medium. Each sample was observed in three fields of view.

Annexin-V-FITC assay of apoptotic cells. The apoptosis rate of the PC12 cells was measured by flow cytometry. PC12 cells 
(2x10 $/$ well) were seeded into 6 -well plates and incubated overnight. After $48 \mathrm{~h}$ of transfection with the relevant siRNA (10 $\mu \mathrm{l} /$ well) or plasmid $(1 \mu \mathrm{g} / \mathrm{well})$, the cells were collected and subjected to Annexin V-FITC-propidium iodide double staining according to the manufacturer's protocols as previously described (39). The cells were analyzed using a BD FACSAria flow cytometer (BD Biosciences) with CellQuest software 5.1 (Becton-Dickinson and Company).

Ethics statement. Human experiments were performed in accordance with relevant approved guidelines and regulations, and were approved by Renmin Hospital of Wuhan University's Institutional Ethics Committee of the Faculty of Medicine [approval no. 2012LKSZ (010) H]. The human para-glioblastoma (GBM) tissue used in the present study was collected in a tumor resection performed at the Department of Neurosurgery, Renmin Hospital of Wuhan University (Wuhan, China) in December 2017, and was the temporal lobe of a 59-year-old female patient with GBM. Prior to the collection of a normal human brain tissue next to GBM, written informed consent was obtained from the relatives of the patient according to the principles of the Declaration of Helsinki.

RND3 knockout mice were generated at Texas A\&M University Health Science Center. All animal experiments were approved by the Institutional Animal Care and Use Committee of the Texas A\&M Health Science Center-Houston. According to the Animal Research: Reporting of In Vivo Experiments checklist (40), the animal's physical condition was monitored daily. Chloral hydrate $(350 \mathrm{mg} / \mathrm{kg})$ was injected intraperitoneally during anesthesia of mice. The euthanasia of mice was conducted using $100 \%$ carbon dioxide inhalation, and the displacement rate of carbon dioxide in the chamber was $30 \% / \mathrm{min}$. The death of mice was verified by no spontaneous breathing for 2-3 min with no eyeblink reflex. One mouse in the $\mathrm{RND}^{-/}$group was excluded from the experiment for a premature death due to malnutrition.

Statistical analysis. The data are presented as the mean \pm SEM. Statistical analysis was performed using SPSS v13.0 (SPSS, Inc.). Significant differences between the means of two groups were assessed by an unpaired t-test. Differences among the means of multiple groups were assessed by one-way ANOVA and Tukey's post hoc test. $\mathrm{P}<0.05$ was considered to indicate a statistically significant difference and the results are representative of three independent repeats.

\section{Results}

Rnd3 deletion suppresses apoptosis in the mouse brain. To explore the functions of Rnd3 in the brain, the present study first analyzed Rnd3 expression in the mouse brain using Rnd3-knockout mice (Fig. 1A) generated from an ES cell line by gene trapping. Neither IF nor IHC staining detected Rnd3 signals in the Rnd3 ${ }^{-}$mouse brain, while Rnd3 was mainly expressed in the cytoplasm of the cortex in wild-type mice (Fig. 1A-C). In the IHC staining of the human brain adjacent to glioblastoma tissue, it was observed that the signals of Rnd3 were not in the nucleus but in the cytoplasm, which indicated that Rnd3 of para-GBM tissue exhibited an expression pattern similar to that of the normal mouse brain (Fig. 1D).
Because neuronal apoptosis is widespread in the brain, particularly in most neurological disorders, the present study next explored the possible roles of Rnd3 in brain cell apoptosis. The western blot analysis revealed that the expression levels of cleaved caspase-3, a key apoptotic protease, were significantly decreased in the $R n d 3^{-1-}$ mouse brains compared with in the wild-type mouse brains, in both the cerebral cortex $(\mathrm{P}<0.05$; Fig. $2 \mathrm{~A}$ and $\mathrm{B})$ and hippocampus $(\mathrm{P}<0.05$; Fig. S1A and B). The IF results also indicated that the intensity of the cleaved caspase- 3 signals was lower in the cortex of $R n d 3^{-/}$mouse brains than it was in the wild-type mouse brains (Fig. 2C), both in neurons (Fig. S2A) and astrocytes (Fig. S2B).

Furthermore, TUNEL assays revealed decreased apoptotic signals in the Rnd $3^{-}$mouse brains compared with in the wild-type mouse brains (Fig. 2D). These data suggested that the deletion of Rnd3 suppressed apoptosis in the mouse brain.

RND3 promotes apoptosis in PC12 cells. To determine the role of RND3 in the regulation of apoptosis, the present study investigated the apoptosis rate of PC12 cells (which have an embryonic origin from the neural crest) using overexpression and knockdown approaches. Western blot analysis demonstrated that cleaved caspase-3 protein expression was significantly increased when RND3 was overexpressed $(\mathrm{P}<0.05$; Fig. 3A and $\mathrm{B})$, which was consistent with the results of flow cytometry, which revealed that RND3 overexpression clearly increased the proportion of apoptotic cells $(\mathrm{P}<0.05$; Fig. 3C and D). By contrast, RND3 knockdown reduced the levels of cleaved caspase- 3 compared with the control $(\mathrm{P}<0.05$; Fig. 3E and F). These data suggested that RND3 could promote the apoptosis of PC12 cells.

Rnd3 regulates $P 65$ expression and affects the $N F-\kappa B$ signaling pathway. To further explore the molecular mechanisms of Rnd3 in the regulation of apoptosis, the present study analyzed $\mathrm{NF}-\kappa \mathrm{B}$ signaling in the mouse brain. The western blot analysis results demonstrated that NF- $\kappa \mathrm{B}$ P65 was upregulated in the brains of the $R n d 3^{--}$mice compared with in the wild-type mice $(\mathrm{P}<0.05$; Fig. $4 \mathrm{~A}$ and $\mathrm{B})$, indicating that Rnd3 downregulated $\mathrm{P} 65$ protein expression. IF analysis revealed the upregulation of $\mathrm{P} 65$ protein expression in the cortex of the Rnd $3^{-}$mouse brains compared with that in the brains of the wild-type mice (Fig. 4C). I $\mathrm{B}-\alpha$ is a protein associated with $\mathrm{P} 65$, and the phosphorylation of I $\kappa \mathrm{B}-\alpha$ leads to proteasome-mediated degradation, which results in the release of activated P65, leading to its nuclear translocation $(41,42)$. To investigate the role of Rnd3 in the $\mathrm{NF}-\kappa \mathrm{B}$ signaling pathway, the present study measured the activation of I $\kappa \mathrm{B}-\alpha$ when Rnd3 was downregulated by Myc-Rnd3 in PC12 cells. Compared with Myc control,

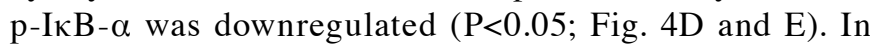
addition, the extent of P65 nuclear translocation in PC12 cells was examined, and compared with those in the Myc control group, the levels of both the cytosolic and nuclear P65 protein were decreased in the Myc-Rnd3 group $(\mathrm{P}<0.05$; Fig. 4F and G). Notably, the expression levels of P65 in the nucleus declined to a greater extent, indicating that Rnd3 can downregulate P65 expression and decrease the nuclear entry of P65, thus suppressing the NF- $\mathrm{B}$ signaling pathway. 

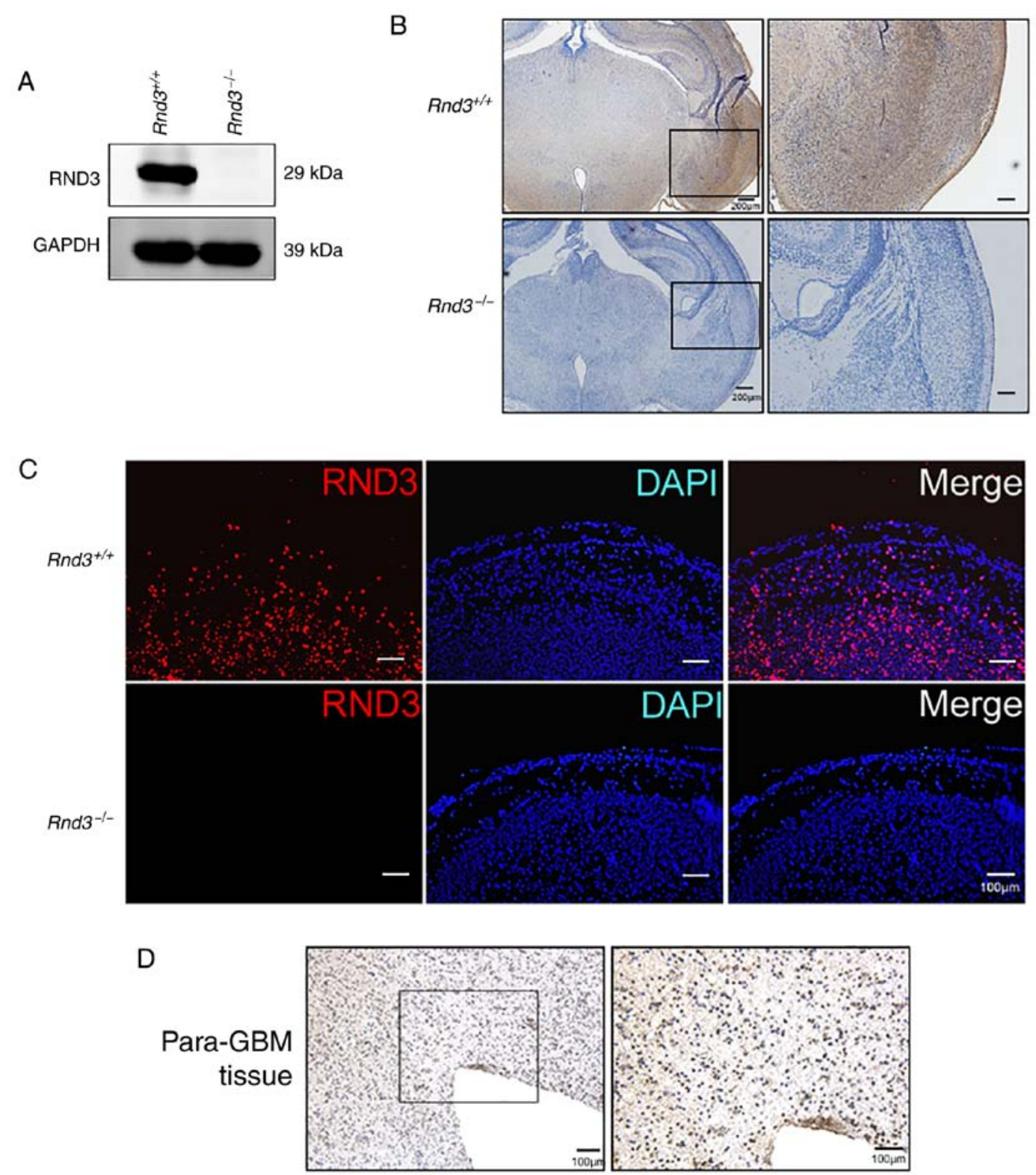

Figure 1. Rnd3 knockout in mice. (A) Rnd3 expression in the brain of wild-type mice according to western blot analysis. Rnd3 expression was completely

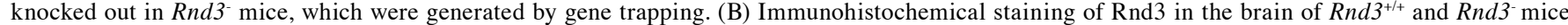
using an anti-RND3 antibody. Enlarged regions in the boxes on the left are shown on the right. Brown color indicates positive signals. Scale bar, $200 \mu \mathrm{m}$ (left) or $100 \mu \mathrm{m}$ (right). (C) Immunofluorescence analysis of Rnd3 protein in the brain of Rnd3 ${ }^{+/+}$and Rnd3 mice using an anti-RND3 antibody (red). Nuclei were stained with DAPI (blue). Scale bar, $100 \mu \mathrm{m}$. (D) Immunohistochemical staining of RND3 in human brain-adjacent GBM tissue (para-GBM) using an anti-RND3 antibody. An enlarged region in the box on the left is shown on the right. Brown color indicates positive signals. Scale bar, $100 \mu \mathrm{m}$. GBM, glioblastoma; Rnd3, Rho family GTPase 3.

These data suggested that Rnd3 may regulate apoptosis via the NF- $\kappa \mathrm{B}$ signaling pathway.

Rnd3 interacts with NF- $\kappa B$ P65 in vivo. To explore the association of RND3 with P65, the present study analyzed their interaction in both $\mathrm{PC} 12$ cells and the mouse brain. Mouse brain lysates were immunoprecipitated with anti-P65 or anti-Rnd3 antibodies, followed by IB with anti-Rnd3 or anti-P65 antibodies. In both cases, interactive proteins were detected (Fig. 5A and B). The IF analysis indicated that RND3/Rnd3 colocalized with P65 in the cytoplasm in the mouse brains (Fig. 5D). Rnd3 was also observed to colocalize with $\mathrm{P} 65$ in the cytoplasm of $\mathrm{PC} 12$ cells using confocal microscopy, while some P65 protein was localized to the nuclei (Fig. 5E). Furthermore, the p65 mRNA level was not altered ( $\mathrm{P}>0.05)$ when RND3 was overexpressed (Fig. 5C). These results indicated that RND3/Rnd3 interacts with P65 in vivo and in vitro.

Rnd3 blocks the anti-apoptotic role of $N F-\kappa B P 65$. To further analyze the role of Rnd 3 and P65 in the regulation of apoptosis, RNA interference (RNAi) was used to knock down Rnd3, P65 or both. Knockdown of P65 upregulated cleaved caspase-3 protein expression, compared with that in the control RNAi group $(\mathrm{P}<0.05$; Fig. $6 \mathrm{~A}$ and $\mathrm{B})$, and increased the proportion of apoptotic cells $(\mathrm{P}<0.05$; Fig. $6 \mathrm{C}$ and $\mathrm{D})$, demonstrating the role of P65 in suppressing apoptosis. A notable decrease in cleaved caspase-3 expression was detected following Rnd3 
A

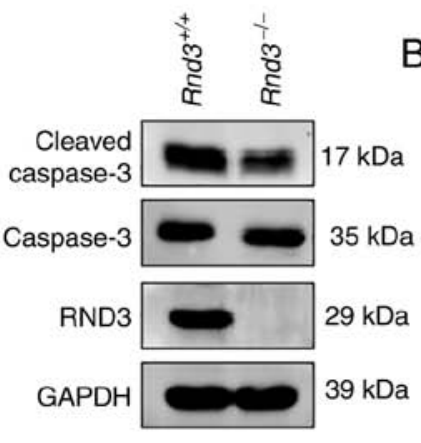

$R n d 3^{+1+}$

\section{B}

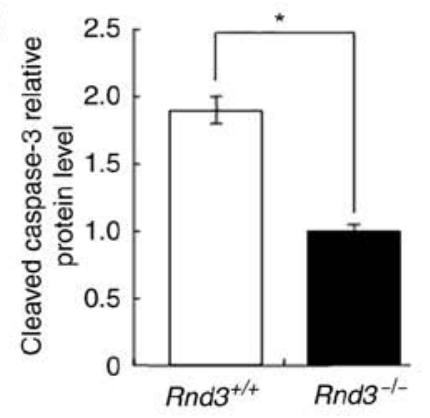

$R n d 3^{-1-}$

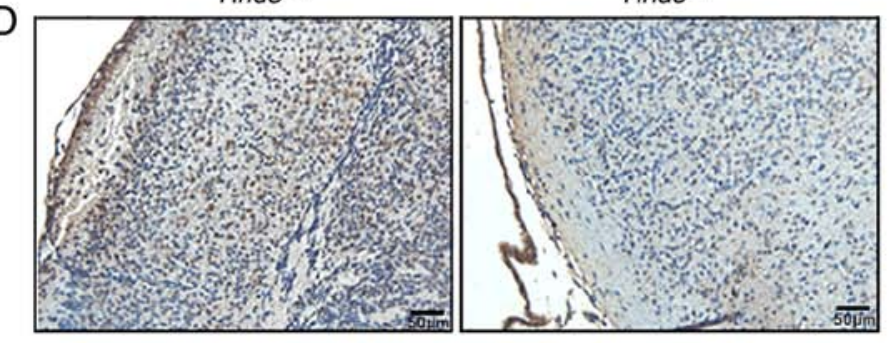

C

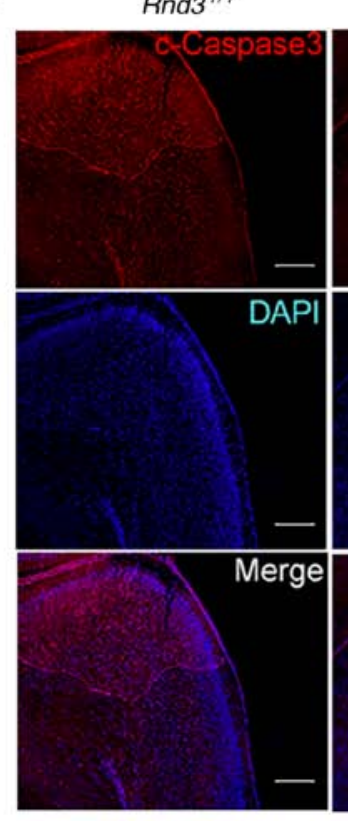

Rnd $3^{-1-}$

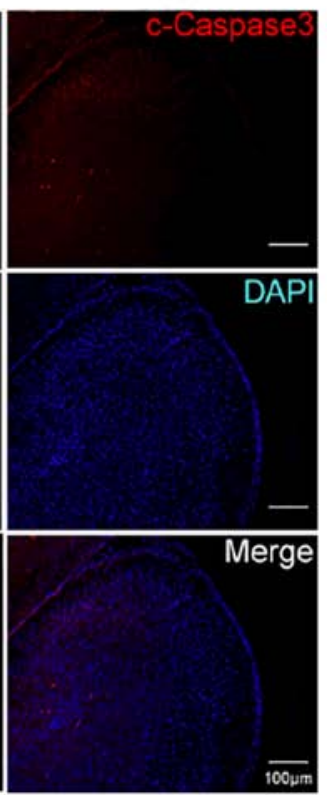

Figure 2. Decreased levels of apoptosis in the Rnd $3^{-}$mouse brain. (A) Western blot analysis revealing a decrease in cleaved caspase-3 protein levels in the brain of 7-day-old Rnd3- mice compared with the levels in samples from mice in the wild-type group. (B) Semi-quantitative analysis of cleaved caspase-3 protein levels in (A). Protein levels were normalized to GAPDH. ${ }^{*} \mathrm{P}<0.05$. $\mathrm{n}=7$ in the RND3 $3^{-/-}$group; $\mathrm{n}=8$ in the RND3 ${ }^{+/+}$group. (C) Immunofluorescent analysis of cleaved caspase-3 expression in the brain of $R n d 3^{+/+}$and $R n d 3^{-/-}$mice using an anti-cleaved caspase-3 antibody (red). Nuclei were stained with DAPI (blue). Scale bar, $100 \mu \mathrm{m}$. (D) TUNEL assays. Decreased apoptotic signals were detected in the Rnd3- mouse brain. Brown color indicates apoptotic signals. Scale bar, $50 \mu \mathrm{m}$. Rnd3, Rho family GTPase 3 .

knockdown, which was reversed by $\mathrm{P} 65$ knockdown $(\mathrm{P}<0.05$; Fig. 6E and F). These data demonstrated that Rnd3 blocked the

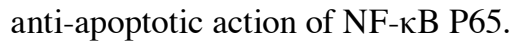

\section{Discussion}

The histopathology of neurodegenerative diseases indicates that neurocytes undergo chronic progressive apoptosis (43). Because neurocytes are nonrenewable, efficient treatment for neurodegenerative diseases is limited. Furthermore, the most commonly used drugs for the treatment of Alzheimer's disease, donepezil and memantine hydrochloride, are expensive and only slow the progression of disease development rather than alleviating symptoms (44). Therefore, alternative treatments of neurodegenerative diseases are required to reduce the neuronal apoptosis rate and maintain cell numbers.

The present study identified a novel role for RND3 as a regulator of apoptosis in the central nervous system. The function of RND3 in promoting apoptosis was demonstrated in PC12 cells using RNAi and overexpression experiments. Notably, Rnd3 was mainly located in the cortex of wild-type mice, but the apoptosis marker, cleaved caspase-3, seemed to decrease more obviously in the hippocampus of $\mathrm{Rnd}^{-/-}$mice. Although it was mainly located in the cortex, Rnd 3 expression could also be detected in the hippocampus, and Rnd 3 expression in the hippocampus of the Rnd $3^{-/}$mice was decreased compared with that of the Rnd $3^{+/+}$mice. This revealed a close relationship between Rnd3 and apoptosis in the central nervous system. The present study also demonstrated that RND3 regulated apoptosis via NF-кB P65 in vivo. Specifically, RND3 blocked the anti-apoptotic role of NF- $\kappa \mathrm{B}$ P65 by downregulating P65, suggesting the importance of RND3-NF- $\mathrm{B}$ P65 signaling integrity in neuropathogenesis. Therefore, RND3-NF-кB P65 represents a novel pathway in the regulation of apoptosis, which may be utilized in the treatment of neurodegenerative diseases. Although Pacary et al (45) reported that Rnd3 knockdown in cortical neuron progenitors did not induce cell death at embryonic stages, the present study mainly focused on the neurons and neuroglial cells of 7-day-old mice, which have different activated intracellular signaling pathways.

RND3 is a member of the GTPase family. Most previous studies of RND3 have focused on its inhibitory effects involving Rho kinase signaling (28). However, evidence suggests that RND3 is involved in multiple biological functions that are likely independent of Rho kinase activity, including mouse neuron development $(32,46)$, neuronal migration $(45)$, and glioblastoma cell proliferation, migration and invasion (37). Additionally, our previous study demonstrated that RND3 was involved in ependymocyte proliferation (33). Combined with the present findings, these studies indicated that RND3 has important roles in the central nervous system and that in-depth studies of its molecular mechanisms in the brain will provide novel insights into the pathogenesis of neurodegenerative diseases.

The present study reported that RND3 decreased p65 protein expression, while the mRNA levels were not altered, indicating that RND3 does not impact p65 mRNA transcription and may instead regulate p65 protein expression in a posttranscriptional manner. Although, to the best of our knowledge, no studies have reported the regulation of p65 by RND3 in the central nervous system, a recent study reported that RND3 regulates the inflammatory response by interacting with p65 and p50 and inhibiting the nuclear translocation of the p65/p50 complex, indicating a protective role for RND3 in myocardial 
A

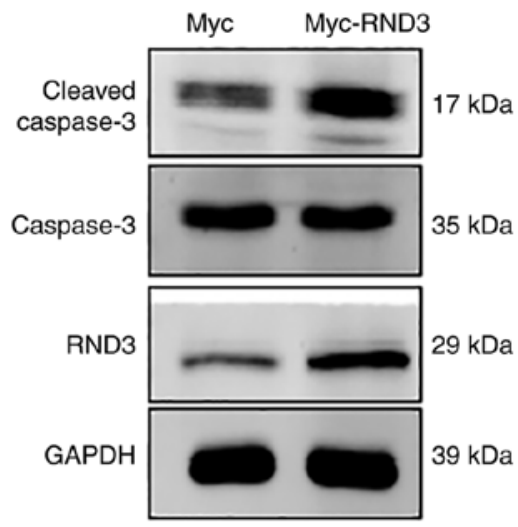

B

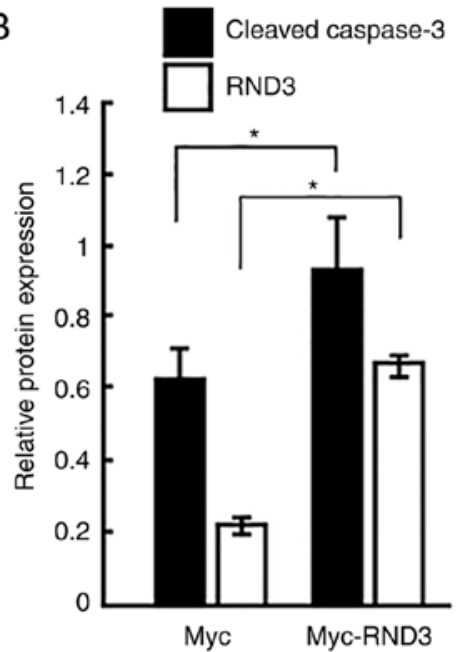

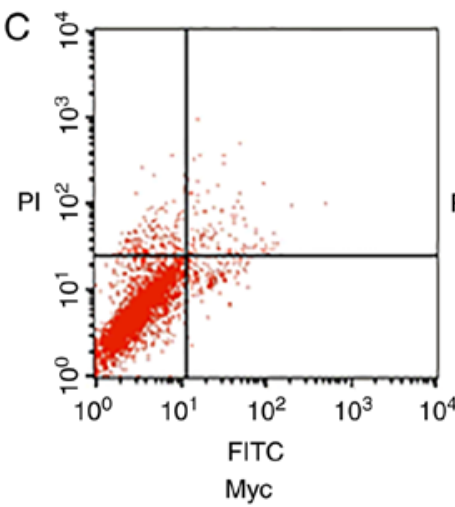

Myc

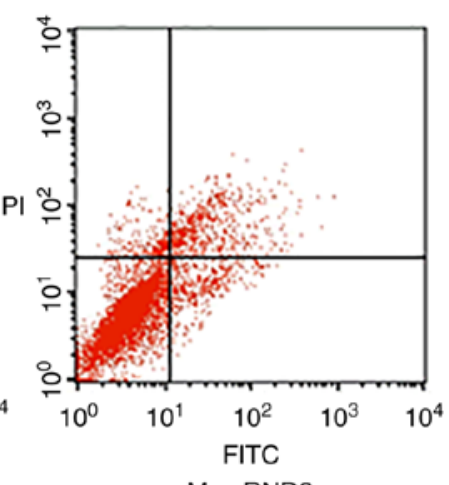

Myc-RND3
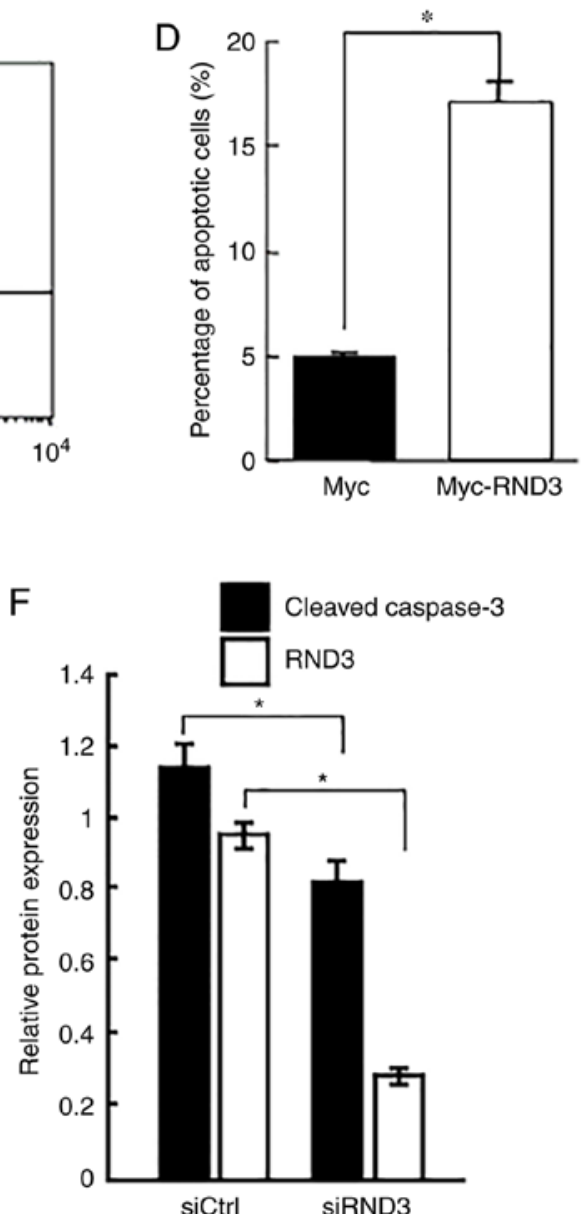

Figure 3. RND3 increases apoptosis in PC12 cells. (A and B) Overexpression of RND3 upregulated c-caspase-3 protein expression. Protein levels of (A) western blots were (B) semi-quantified and normalized to GAPDH. " $\mathrm{P}<0.05$. $n=3$. (C) Percentage of apoptotic cells assessed by flow cytometry. (D) RND3 overexpression promoted apoptosis in $\mathrm{PC} 12$ cells. ${ }^{*} \mathrm{P}<0.05$. n=3. (E) Knockdown of $R N D 3$ decreased c-caspase-3 protein expression in PC12 cells treated with siRND3. siCtrl was used as a control. (F) Relative protein expression levels in the siRND3 and siCtrl groups were semi-quantified and normalized to GAPDH. ${ }^{*} \mathrm{P}<0.05$. n=3. c-, cleaved; Ctrl, control; RND3, Rho family GTPase 3; si, small interfering RNA.

infarction (47). Several previous studies have demonstrated that RND3 is a downstream target of p53, resulting in the inhibition of Rho associated coiled-coil containing protein kinase 1 (ROCK1)-mediated apoptosis in certain types of tumor $(48,49)$. Furthermore, RND3 is associated with the hyperactivation of ROCK1 signaling in mouse hearts, leading to apoptotic cardiomyopathy and heart failure (50).
$\mathrm{NF}-\kappa \mathrm{B}$ is involved in multiple activities through various extracellular signals, such as neurotransmitters, neuropeptides, neurotrophins, cytokines and neural cell adhesion molecules, in the nervous system (51). Furthermore, NF- $\mathrm{kB}$ signaling provides neuroprotective functions through its role in the survival of certain populations of peripheral and central neurons (52). NF- $\mathrm{\kappa B}$ also protects neurons from glutamate, 

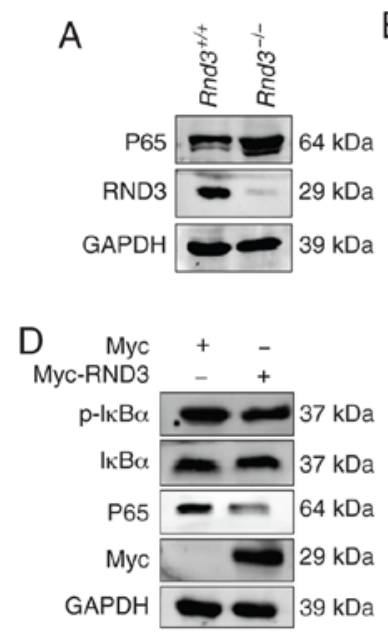
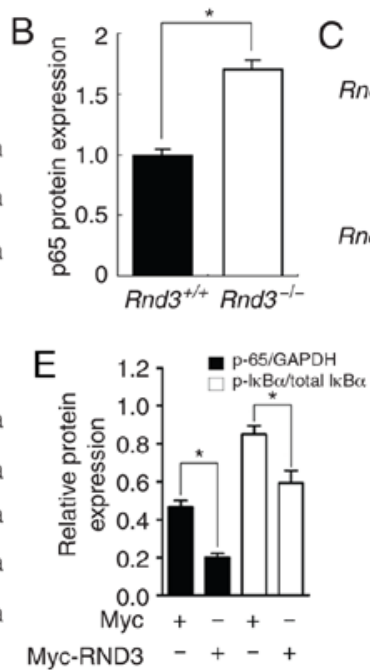
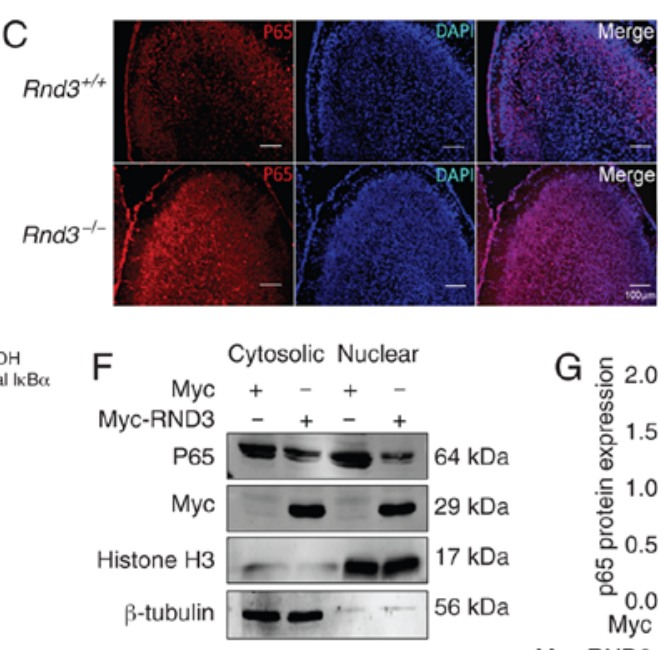

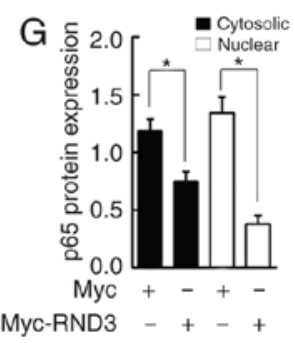

Figure 4. Rnd3 regulates P65 expression and affects the NF- $\kappa \mathrm{B}$ signaling pathway. (A) Western blot analysis revealing that P65 protein expression was increased in the $R n d 3^{-}$mouse brain compared with in the wild-type mouse brain. (B) Protein levels in western blots were semi-quantified. $\mathrm{P}<0.05$. $\mathrm{n}=7$ in the $\mathrm{RND}^{-/-}$group; $\mathrm{n}=8$ in the RND3 ${ }^{+/+}$group. (C) Immunofluorescence analysis revealing higher P65 expression in Rnd3 compared with Rnd $3^{+/+}$mouse brains, using an anti-P65 antibody (red). Nuclei were stained with DAPI (blue). Scale bar, $100 \mu \mathrm{m}$. (D) Western blot analysis demonstrating that p-IкB- $\alpha$ protein expression was decreased following treatment with Myc-Rnd3 in PC12 cells. Myc was used as a control. (E) Relative protein expression levels in the Myc-Rnd3 and Myc groups were semi-quantified and normalized to GAPDH. ${ }^{*} \mathrm{P}<0.05$. $\mathrm{n}=3$. (F) Western blot analysis revealing that P65 protein was decreased in the cytosol and nucleus following treatment with Myc-Rnd3, while nuclear P65 expression was decreased more obviously in PC12 cells. (G) Cytosolic and nuclear P65 protein expression in the Myc-Rnd3 and Myc groups were semi-quantified and normalized to $\beta$-tubulin and histone $\mathrm{H} 3$. * $\mathrm{P}<0.05$. $\mathrm{n}=3$. I $\kappa \mathrm{B}-\alpha$, inhibitor of NF- $\kappa$ B- $\alpha$; p-, phosphorylated; Rnd3, Rho family GTPase 3.
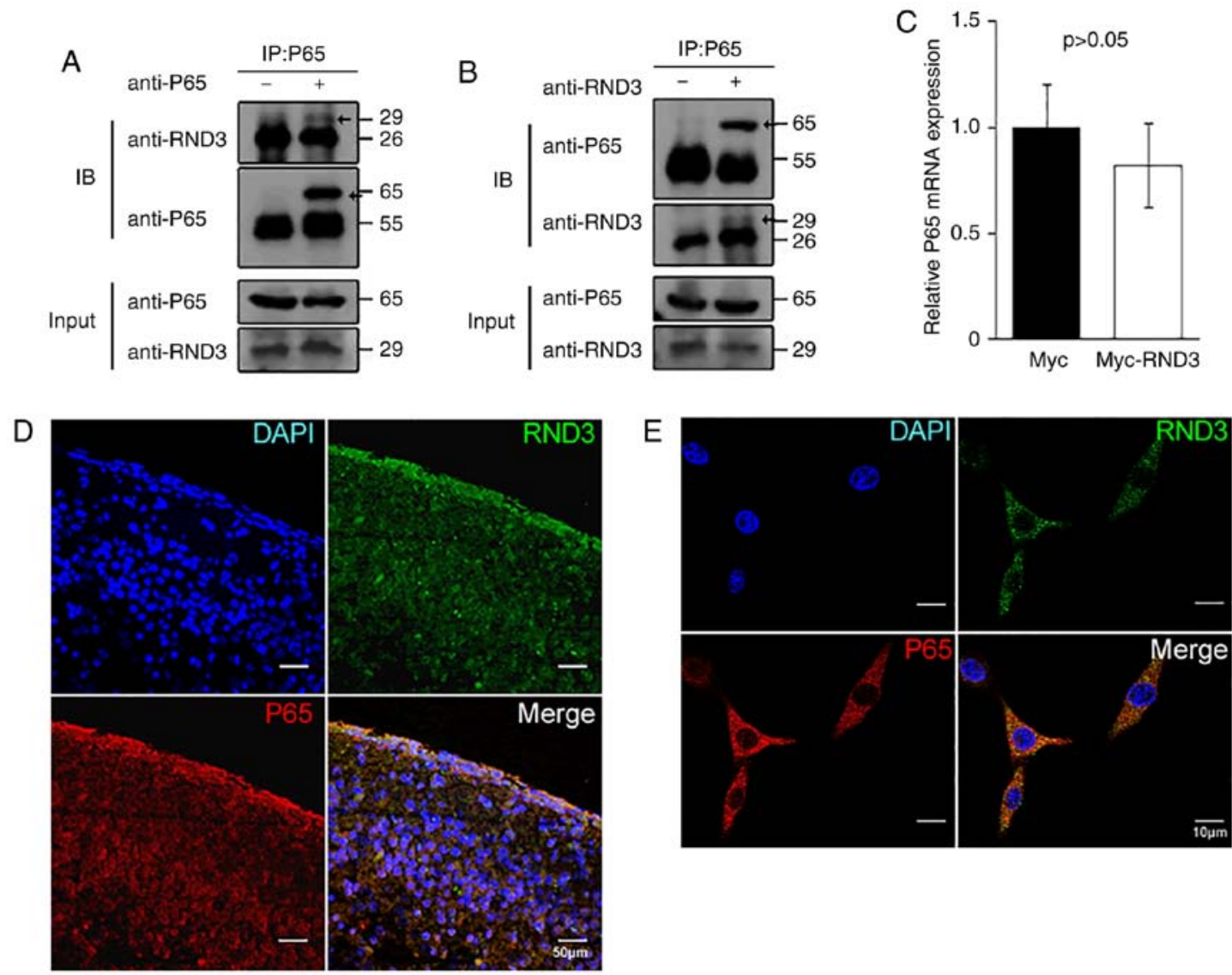

Figure 5. RND3 interacts with P65. (A) A Rnd3 positive signal in immunoblotting of the mouse brain lysates which was immunoprecipitated with the antibody against P65. (B) Lysates immunoprecipitated with anti-RND3 were incubated with an antibody against P65, revealing a positive signal of P65. Arrows indicate the immunoprecipitated band. (C) Compared with that in the myc group, mRNA expression of P65 was not significantly different in the myc-RND3 group $(\mathrm{P}>0.05)$. (D) Co-localization of RND3 with P65 protein in the brain of adult mice. Immunofluorescence assays were performed in brain sections using anti-RND3 (green) and anti-P65 (red) antibodies. Merged images are shown in the lower right panel. Nuclei were stained with DAPI (blue). Scale bar, $50 \mu \mathrm{m}$. (E) Immunofluorescence staining revealing the co-localization of endogenous RND3 (green) and p65 (red) proteins in PC12 cells. Nuclei were stained with DAPI (blue). Scale bar, $10 \mu \mathrm{m}$. RND3, Rho family GTPase 3; IB, immunoblotting; IP, immunoprecipitation. 
B

A
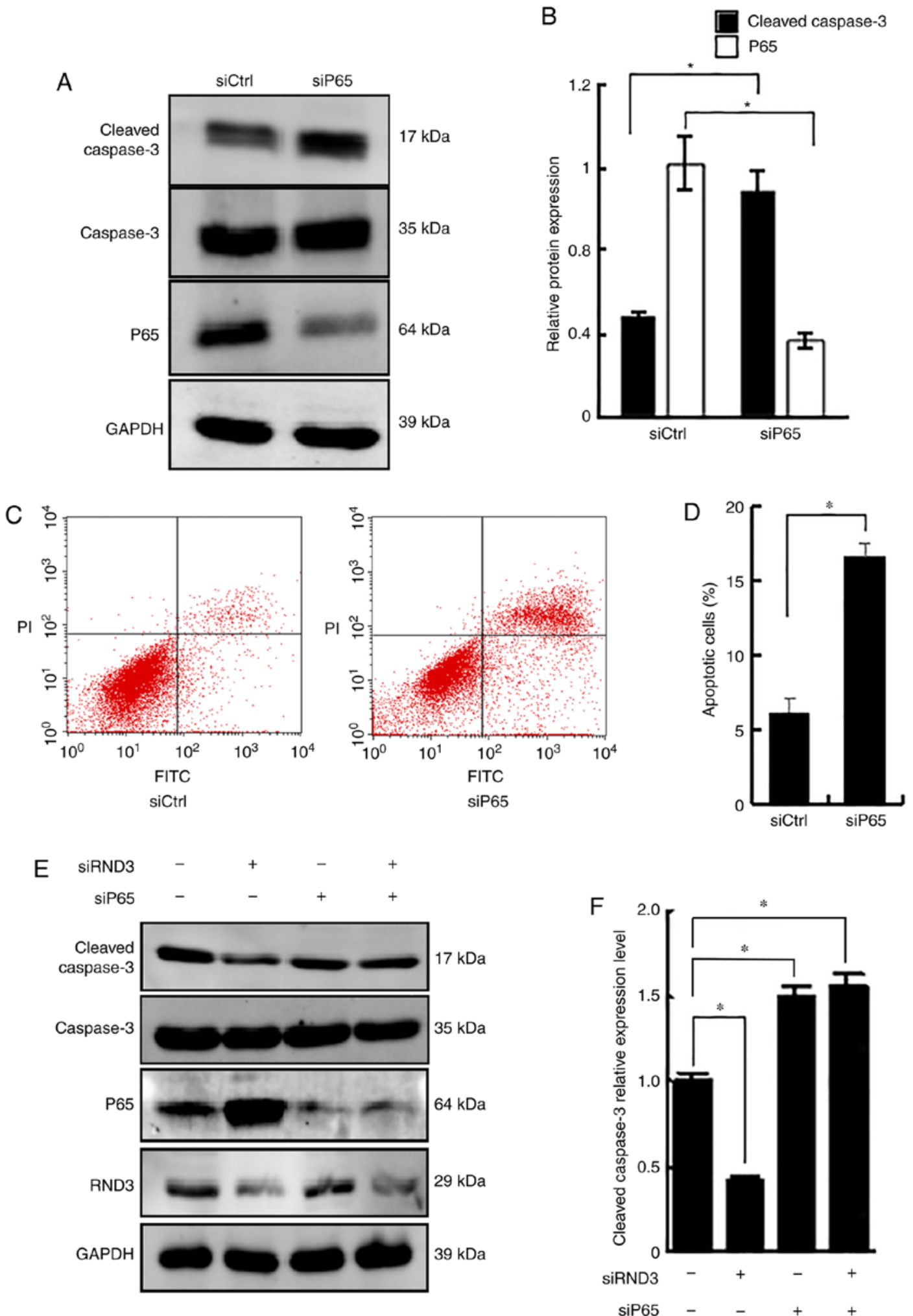

Figure 6. RND3 blocks the anti-apoptotic role of NF-kB P65. (A and B) Knockdown of P65 promoted apoptosis in PC12 cells. c-caspase-3 protein expression was upregulated following siRNA knockdown of P65. Protein levels in (A) western blots were (B) semi-quantified. "P<0.05. $n=3$. (C) Flow cytometry assays demonstrated that the percentage of apoptotic cells was increased following P65 knockdown. (D) The percentage of apoptotic cells was quantified. ${ }^{*} \mathrm{P}<0.05$. $\mathrm{n}=3$. (E and F) Western blot analysis of c-caspase-3 expression following knockdown of RND3, P65 or both. Protein levels of (E) western blots were (F) semi-quantified. "P<0.05. n=3. c-, cleaved; Ctrl, control; RND3, Rho family GTPase 3; si, small interfering RNA.

oxidative stress and amyloid $\beta$-peptide (53). Notably, vascular endothelial growth factor-mediated NF- $\kappa \mathrm{B}$ activation protected PC12 cells from damage induced by hypoxia through P65 nuclear translocation (54), while p65 siRNA and a p65-specific inhibitor promoted apoptosis in cultured fibroblasts (55).

The aforementioned anti-apoptotic effect of P65 was consistent with the present observations of the involvement 
of the RND3-P65 signaling pathway in apoptosis regulation. However, an opposite function of p65 in the PDCD5-mediated apoptosis in cancer cells has been reported, in which the NF- $\kappa \mathrm{B}$ signaling pathway induced tumor cell apoptosis via P65 (56). The transfection of constructs encoding p65 decreased the expression levels of cell proliferation markers but not apoptosis markers in ovarian cells (57). The differences in the results of these studies may reflect the activation of different signaling pathways in various cell types and/or physiological conditions, which should be clarified.

The present study demonstrated that RND3 attenuated the NF- $\mathrm{BB}$ P65 signaling pathway along with cell apoptosis in the brain. Additionally, it was demonstrated that RND3 interacted with P65, leading to the inhibition of the NF- $\mathrm{kB}$ signaling pathway, which increased cell apoptosis in the central nervous system in vivo and in vitro. These findings may help comprehend the regulation of the NF- $\mathrm{kB}$ P65 signaling pathway and potential therapeutic uses of RND3 in the brain.

\section{Acknowledgements}

The authors would like to thank Dr Jiang Chang, Dr Xiangsheng Yang and Dr Dai Yuan of Texas A\&M University Health Science Center (Bryan, USA) for generating and providing RND3 knockout mice and Dr Rongjia Zhou and Dr Hanhua Cheng (College of Life Sciences of Wuhan University, Wuhan, China) for providing the Flag-p65 plasmid.

\section{Funding}

The present study was supported by the National Natural Science Foundation of China (grant nos. 81502175 and 81371390) and Hubei Province Health and Family Planning Scientific Research Project (grant no. WJ2017Q008).

\section{Availability of data and materials}

The datasets used and/or analyzed during the current study are available from the corresponding author on reasonable request.

\section{Authors' contributions}

BL designed the research. HD, QS, YZ, YL and FY carried out the experimental work. SM analyzed the data and wrote the paper. All authors read and approved the final manuscript.

\section{Ethics approval and consent to participate}

All animal and human experiments were performed in accordance with the relevant approved guidelines and regulations, and were approved by the Ethics Committee of Wuhan University [approval no. 2012LKSZ (010) H]. Prior to sample collection, written informed consent was obtained from the relatives of this patient with impaired consciousness.

\section{Patient consent for publication}

Not applicable.

\section{Competing interests}

The authors declare that they have no competing interests.

\section{References}

1. Kerr JF, Wyllie AH and Currie AR: Apoptosis: A basic biological phenomenon with wide-ranging implications in tissue kinetics. Br J Cancer 26: 239-257, 1972.

2. Elmore S: Apoptosis: A review of programmed cell death. Toxicol Pathol 35: 495-516, 2007.

3. Fuchs Y and Steller H: Live to die another way: Modes of programmed cell death and the signals emanating from dying cells. Nat Rev Mol Cell Biol 16: 329-344, 2015.

4. Fuchs Y and Steller H: Programmed cell death in animal development and disease. Cell 147: 742-758, 2011.

5. Ryoo HD, Gorenc T and Steller H: Apoptotic cells can induce compensatory cell proliferation through the JNK and the Wingless signaling pathways. Dev Cell 7: 491-501, 2004.

6. Yamaguchi Y and Miura M: Programmed cell death in neurodevelopment. Dev Cell 32: 478-490, 2015.

7. Buss RR, Gould TW, Ma J, Vinsant S, Prevette D, Winseck A, Toops KA, Hammarback JA, Smith TL and Oppenheim RW: Neuromuscular development in the absence of programmed cell death: Phenotypic alteration of motoneurons and muscle. J Neurosci 26: 13413-13427, 2006.

8. Ferrer I, Soriano E, del Rio JA, Alcántara S and Auladell C: Cell death and removal in the cerebral cortex during development. Prog Neurobiol 39: 1-43, 1992.

9. Kuan CY, Flavell RA and Rakic P: Programmed cell death in mouse brain development. Results Probl Cell Differ 30: 145-162, 2000.

10. Haydar TF, Nowakowski RS, Yarowsky PJ and Krueger BK: Role of founder cell deficit and delayed neuronogenesis in microencephaly of the trisomy 16 mouse. J Neurosci 20: 4156-4164, 2000.

11. Yeo W and Gautier J: Early neural cell death: Dying to become neurons. Dev Biol 274: 233-244, 2004.

12. de la Rosa EJ and de Pablo F: Cell death in early neural development: Beyond the neurotrophic theory. Trends Neurosci 23: 454-458, 2000.

13. Oppenheim RW: Cell death during development of the nervous system. Annu Rev Neurosci 14: 453-501, 1991.

14. Verney C, Takahashi T, Bhide PG, Nowakowski RS and Caviness VS Jr: Independent controls for neocortical neuron production and histogenetic cell death. Dev Neurosci 22: $125-138,2000$.

15. Favaloro B, Allocati N, Graziano V, Di Ilio C and De Laurenzi V: Role of apoptosis in disease. Aging (Albany NY) 4: 330-349, 2012.

16. Hamblin MR: Photobiomodulation for traumatic brain injury and stroke. J Neurosci Res 96: 731-743, 2018.

17. Sureda A, Capó X and Tejada S: Neuroprotective effects of flavonoid compounds on neuronal death associated to Alzheimer's disease. Curr Med Chem 26: 5124-5136, 2019.

18. Gitler AD, Dhillon P and Shorter J: Neurodegenerative disease: Models, mechanisms, and a new hope. Dis Model Mech 10: 499-502, 2017.

19. Egawa N, Lok J, Washida K and Arai K: Mechanisms of axonal damage and repair after central nervous system injury. Transl Stroke Res 8: 14-21, 2017.

20. Li C, Wang D, Wu W, Yang W, Ali Shah SZ, Zhao Y, Duan Y, Wang L, Zhou X, Zhao D and Yang L: DLP1-dependent mitochondrial fragmentation and redistribution mediate prion-associated mitochondrial dysfunction and neuronal death. Aging Cell 17: e12693, 2018.

21. Kischkel FC, Lawrence DA, Chuntharapai A, Schow P, Kim KJ and Ashkenazi A: Apo2L/TRAIL-dependent recruitment of endogenous FADD and caspase- 8 to death receptors 4 and 5 . Immunity 12: 611-620, 2000 .

22. Sharma D and Kanneganti TD: Inflammatory cell death in intestinal pathologies. Immunol Rev 280: 57-73, 2017.

23. Bleicken S, Landeta O, Landajuela A, Basañez G and García-Sáez AJ: Proapoptotic Bax and Bak proteins form stable protein-permeable pores of tunable size. J Biol Chem 288: 33241-33252, 2013.

24. Liu L, Zhang R, Liu K, Zhou H, Tang Y, Su J, Yu X, Yang $X$, Tang $M$ and Dong Q: Tissue kallikrein alleviates glutamate-induced neurotoxicity by activating ERK1. J Neurosci Res 87: 3576-3590, 2009. 
25. Sheikh MS and Huang Y: Death receptor activation complexes: It takes two to activate TNF receptor 1. Cell Cycle 2: 550-552, 2003.

26. Bourteele S, Oesterle K, Weinzierl AO, Paxian S, Riemann M, Schmid RM and Planz O: Alteration of NF-kappaB activity leads to mitochondrial apoptosis after infection with pathological prion protein. Cell Microbiol 9: 2202-2217, 2007.

27. Fiegen D, Blumenstein L, Stege P, Vetter IR and Ahmadian MR: Crystal structure of Rnd3/RhoE: Functional implications. FEBS Lett 525: 100-104, 2002.

28. Jie W, Andrade KC, Lin X, Yang X, Yue X and Chang J: Pathophysiological functions of Rnd3/RhoE. Compr Physiol 6: 169-186, 2015.

29. Foster R, Hu KQ, Lu Y, Nolan KM, Thissen J and Settleman J: Identification of a novel human Rho protein with unusual properties: GTPase deficiency and in vivo farnesylation. Mol Cell Biol 16: 2689-2699, 1996.

30. Riento K, Guasch RM, Garg R, Jin B and Ridley AJ: RhoE binds to ROCK I and inhibits downstream signaling. Mol Cell Biol 23 : 4219-4229, 2003.

31. Klein RM and Aplin AE: Rnd3 regulation of the actin cytoskeleton promotes melanoma migration and invasive outgrowth in three dimensions. Cancer Res 69: 2224-2233, 2009.

32. Pacary E, Azzarelli R and Guillemot F: Rnd 3 coordinates early steps of cortical neurogenesis through actin-dependent and -independent mechanisms. Nat Commun 4: 1635, 2013.

33. Lin X, Liu B, Yang X, Yue X, Diao L, Wang J and Chang J: Genetic deletion of Rnd3 results in aqueductal stenosis leading to hydrocephalus through up-regulation of Notch signaling. Proc Natl Acad Sci USA 110: 8236-8241, 2013

34. Yang X, Wang T, Lin X, Yue X, Wang Q, Wang G, Fu Q, Ai X, Chiang DY, Miyake CY, et al: Genetic deletion of Rnd3/RhoE results in mouse heart calcium leakage through upregulation of protein kinase A signaling. Circ Res 116: e1-e10, 2015.

35. Sheng Y, Song Y, Li Z, Wang Y, Lin H, Cheng $\mathrm{H}$ and Zhou R: RAB37 interacts directly with ATG5 and promotes autophagosome formation via regulating ATG5-12-16 complex assembly. Cell Death Differ 25: 918-934, 2018.

36. Yuan J, Zhang Y, Sheng Y, Fu X, Cheng H and Zhou R: MYBL2 guides autophagy suppressor VDAC2 in the developing ovary to inhibit autophagy through a complex of VDAC2-BECN1-BCL2L1 in mammals. Autophagy 11: 1081-1098, 2015.

37. Liu B, Dong H, Lin X, Yang X, Yue X, Yang J, Li Y, Wu L, Zhu X, Zhang S, et al: RND3 promotes Snail 1 protein degradation and inhibits glioblastoma cell migration and invasion. Oncotarget 7 : 82411-82423, 2016.

38. Sun Q, Dong H, Li Y, Yuan F, Xu Y, Mao S, Xiong X, Chen Q and Liu B: Small GTPase RHOE/RND3, a new critical regulator of NF- $\mathrm{kB}$ signalling in glioblastoma multiforme? Cell Prolif 52: e12665, 2019

39. Liu B, Guo Z, Dong H, Daofeng T, Cai Q, Ji B, Zhang S, Wu L, Wang J, Wang L, et al: LRIG1, human EGFR inhibitor, reverses multidrug resistance through modulation of $\mathrm{ABCB} 1$ and $\mathrm{ABCG} 2$. Brain Res 1611: 93-100, 2015.

40. Kilkenny C, Browne W, Cuthill IC, Emerson M and Altman DG; NC3Rs Reporting Guidelines Working Group: Animal research: Reporting in vivo experiments: The ARRIVE guidelines. Br J Pharmacol 160: 1577-1579, 2010.

41. Brockman JA, Scherer DC, McKinsey TA, Hall SM, Qi X, Lee WY and Ballard DW: Coupling of a signal response domain in I kappa B alpha to multiple pathways for NF-kappa B activation. Mol Cell Biol 15: 2809-2818, 1995.
42. Chen ZJ, Parent L and Maniatis T: Site-specific phosphorylation of IkappaBalpha by a novel ubiquitination-dependent protein kinase activity. Cell 84: 853-862, 1996.

43. Waldmeier PC and Tatton WG: Interrupting apoptosis in neurodegenerative disease: Potential for effective therapy? Drug Discov Today 9: 210-218, 2004.

44. Briggs R, Kennelly SP and O'Neill D: Drug treatments in Alzheimer's disease. Clin Med (Lond) 16: 247-253, 2016.

45. Pacary E, Heng J, Azzarelli R, Riou P, Castro D, Lebel-Potter M, Parras C, Bell DM, Ridley AJ, Parsons M and Guillemot F: Proneural transcription factors regulate different steps of cortical neuron migration through Rnd-mediated inhibition of RhoA signaling. Neuron 69: 1069-1084, 2011.

46. Mocholí E, Ballester-Lurbe B, Arqué G, Poch E, Peris B, Guerri C, Dierssen M, Guasch RM, Terrado J and Pérez-Roger I: RhoE deficiency produces postnatal lethality, profound motor deficits and neurodevelopmental delay in mice. PLoS One 6: e19236, 2011.

47. Dai Y, Song J, Li W, Yang T, Yue X, Lin X, Yang X, Luo W, Guo J, Wang X, et al: RhoE fine-tunes inflammatory response in myocardial infarction. Circulation 139: 1185-1198, 2019.

48. Ongusaha PP, Kim HG, Boswell SA, Ridley AJ, Der CJ, Dotto GP, Kim YB, Aaronson SA and Lee SW: RhoE is a pro-survival p53 target gene that inhibits ROCK I-mediated apoptosis in response to genotoxic stress. Curr Biol 16: 2466-2472, 2006.

49. Zhu Y, Zhou J, Xia H, Chen X, Qiu M, Huang J, Liu S, Tang Q, Lang N, Liu Z, et al: The Rho GTPase RhoE is a p53-regulated candidate tumor suppressor in cancer cells. Int J Oncol 44: 896-904, 2014.

50. Yue X, Yang X, Lin X, Yang T, Yi X, Dai Y, Guo J, Li T, Shi J, Wei L, et al: Rnd3 haploinsufficient mice are predisposed to hemodynamic stress and develop apoptotic cardiomyopathy with heart failure. Cell Death Dis 5: e1284, 2014.

51. Gutierrez H and Davies AM: Regulation of neural process growth, elaboration and structural plasticity by NF- $\kappa \mathrm{B}$. Trends Neurosci 34: 316-325, 2011.

52. Mémet S: NF-kappaB functions in the nervous system: From development to disease. Biochem Pharmacol 72: 1180-1195, 2006.

53. Qin ZH, Tao LY and Chen X: Dual roles of NF- $\kappa$ B in cell survival and implications of NF-kappaB inhibitors in neuroprotective therapy. Acta Pharmacol Sin 28: 1859-1872, 2007.

54. Mo SJ, Hong J, Chen X, Han F, Ni Y, Zheng Y, Liu JQ, Xu L, $\mathrm{Li} \mathrm{Q}$, Yang $\mathrm{XH}$, et al: VEGF-mediated NF- $\kappa \mathrm{B}$ activation protects PC12 cells from damage induced by hypoxia. Neurosci Lett 610 : 54-59, 2016.

55. Chen S, Jiang S, Zheng W, Tu B, Liu S, Ruan H and Fan C: RelA/p65 inhibition prevents tendon adhesion by modulating inflammation, cell proliferation, and apoptosis. Cell Death Dis 8: e2710, 2017.

56. Murshed F, Farhana L, Dawson MI and Fontana JA: NF- $\kappa B$ p65 recruited SHP regulates PDCD5-mediated apoptosis in cancer cells. Apoptosis 19: 506-517, 2014.

57. Sirotkin AV, Dekanová P, Harrath AH, Alwasel SH and Vašíček D: Interrelationships between sirtuin 1 and transcription factors p53 and NF- $\mathrm{KB}$ (p50/p65) in the control of ovarian cell apoptosis and proliferation. Cell Tissue Res 358: 627-632, 2014.

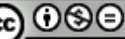

This work is licensed under a Creative Commons Attribution-NonCommercial-NoDerivatives 4.0 International (CC BY-NC-ND 4.0) License. 